\title{
Deep venous thrombosis in patients with liver cirrhosis: Incidence and management
}

\author{
Ahmed Saif Al-Islam¹, MD; Mahmoud Saif Al-Islam², MD; Mohamed Zaki ${ }^{3}$ MD
}

\author{
1) Vascular Surgery Department, Sohag University, Sohag, Egypt. \\ 2) Tropical Medicine and Gastroentrology Department, Sohag University, \\ Sohag, Egypt. \\ 3) Diagnostic Radiology Department, Sohag University, Sohag, Egypt.
}

The purpose of this study is to investigate the incidence and predisposing factors of lower limb deep venous thrombosis (DVT) in cirrhotic patients, and to evaluate the use of anticoagulation therapy (AT) with low molecular weight heparin (LMWH) and warfarin for management of DVT in these patients. The study was conducted on 622 cirrhotic patients from whom the incidence of lower limb DVT was obtained. Six cirrhotic patients with lower limb DVT and twenty four cirrhotic controls were fully investigated and compared. The patients and controls were age, sex and Child-Pugh score matched. All the patients were assessed according to a protocol including prothrombin time, prothrombin concentration, international normalized ratio (INR), protein C, protein S, antithrombin III, serum bilirubin, serum albumin, platelet counts, HBs-Ag and HCV antibody. Results revealed that the prevalence of DVT in our cirrhotic patients was $0.96 \%$. The use of AT in cirrhotic patients needs meticulous follow up for early management of any complications and the screening for esophageal varices with prophylactic band ligation if risk signs were present is of great importance.

\section{Introduction:}

Liver cirrhosis is accompanied by multiple changes in the hemostatic system due to the reduced levels of natural inhibitors of coagulation and coagulation factors because of the impaired hepatic synthetic activity. ${ }^{1}$ Thus, the global effect of liver disease on hemostasis is complex, and therefore, patients with liver cirrhosis can experience bleeding or thrombotic complications. ${ }^{2}$

Studies investigating the incidence of venous thromboembolism in patients with liver cirrhosis have reported a risk equal to $^{3}$ or less than ${ }^{4}$ that of other medically ill hospitalized patients.

In severe liver disease the protein levels that are synthesized in the liver are reduced as the synthetic capacity is lost. Thus, levels of both pro-and anticoagulant proteins decrease as liver disease progresses. A relatively balanced reduction in pro-and anticoagulant activity does not result in a net hyper-or hypocoagulable state until the loss of liver synthetic capacity is severe. Local endothelial dysfunction can lead to the development of a hypercoagulable state and thrombosis. ${ }^{5}$

The treatment of deep vein thrombosis and pulmonary embolism is well established and evidence-based guidelines are regularly updated. ${ }^{6}$ Anticoagulant therapy in cirrhotic patients is complex because of an imbalance in hemostasis, as well as changes in the pharmacodynamics of anticoagulants in liver insufficiency. Heparin and acenocoumarol have an average lifespan that is lengthened by their decreased metabolism; vitamin K deficit strengthens the action of acenocoumarol. ${ }^{7}$

\section{Aim of the work}

The aim of this study is to know the incidence and predisposing factors of lower limb deep venous thrombosis (DVT) in 
cirrhotic patients, and to evaluate the use of anticoagulation therapy (AT) with low molecular weight heparin (LMWH) and warfarin for management of DVT in these patients.

\section{Patients:}

This study was conducted on 622 cirrhotic patients who were admitted to Tropical Medicine and Gastroenterology Department in Sohag University Hospital from year 2007 to 2009. If a patient had multiple admissions during the study period, we only included the first admission during which abdominal ultrasound and lower extremity venous Duplex ultrasound was performed. The study included 2 groups. Group 1 contained 6 cirrhotic patients with lower limb DVT. Group 2 contained 24 cirrhotic patients without DVT enrolled as cirrhotic controls. The patients and controls were age, sex and Child-Pugh score matched.

\section{Methods}

Patients included in the study were given a clear explanation of the objectives and plan of the study and signed informed consent to participate in the study. All the patients and controls were assessed according to the following protocol: age, gender, prothrombin time, prothrombin concentration, international normalized ratio (INR), protein C, protein $\mathrm{S}$, antithrombin III, serum bilirubin, serum albumin, platelet counts, HBs-Ag, AntiHCV and Child-Pugh score. Patients with diagnosis of lower limb DVT were evaluated for anticoagulation therapy.

Deep vein thrombosis was detected using Duplex ultrasonography (Siemens Sonoline G50) on the venous system in the lower extremity. The Duplex ultrasonographic criteria for DVT are as follows: no flow signal, direct clot visualization, loss of augmentation and incompressibility of the vein. ${ }^{8}$

For patients with lower limb DVT, esophagogastroduodenoscopy (EGD) was done and prophylactic repeated band ligation was done for patients with risk signs of bleeding and a beta blocker was given. Then LMWH (enoxaparin, 1mg/ $\mathrm{kg} / \mathrm{d}$ ) in two divided doses was administered subcutaneously for five days followed by the vitamin $\mathrm{K}$ antagonists warfaren (Marivan $1 \mathrm{mg}$ tablet) started in the last two days of LMWH treatment with a target prothrombin concentration not less than $40 \%$ and INR of 2-3. Also, the patients received Diosnim (Daflon $500 \mathrm{mg}$ tablet) twice daily and salt free albumin. The patients were followed up twice weekly for 3 months by doing clinical evaluation, venous Duplex ultrasound examination, prothrombin concentration and INR.

\section{Statistical analyses:}

The data was analyzed by SPSS 10.0 software. Continuous data was expressed as mean $\pm \mathrm{SD}$, while the categorical data was expressed as a number and percentage. The incidence of lower limb DVT in cirrhotic patients was calculated from the total number of patients during the study period. Comparisons of differences between the two groups were performed by using the Student's t-test for the continuous data, while categorical data were compared by using the Fisher's exact test. $\mathrm{P}$ values of less than 0.05 were considered significant.

\section{Results:}

Over two years, we included 622 cirrhotic patients, only $6(0.96 \%)$ of them had lower limb DVT as diagnosed clinically by a swollen lower limb with hotness and tenderness and confirmed by Duplex ultrasonography Figures $(\mathbf{1 , 2})$. Hepatitis $C$ was the most common underlying cause of liver cirrhosis found in 448 (72\%) patients, followed by hepatitis B in 85 (14\%) patients. 61 (10\%) patients had negative serology but with past history of bilhariziasis, 22 (3\%) patients had cryptogenic cirrhosis, and 6 (1\%) patients were alcoholic.

The six patients with lower limb DVT received AT. Their mean age was $60.17 \pm 4.17$ years. Three patients were Child-Pugh class A, one patient was Child-Pugh class B, and 2 patients were Child-Pugh class C.

The main clinical characteristics and laboratory values of cirrhotic patients with 


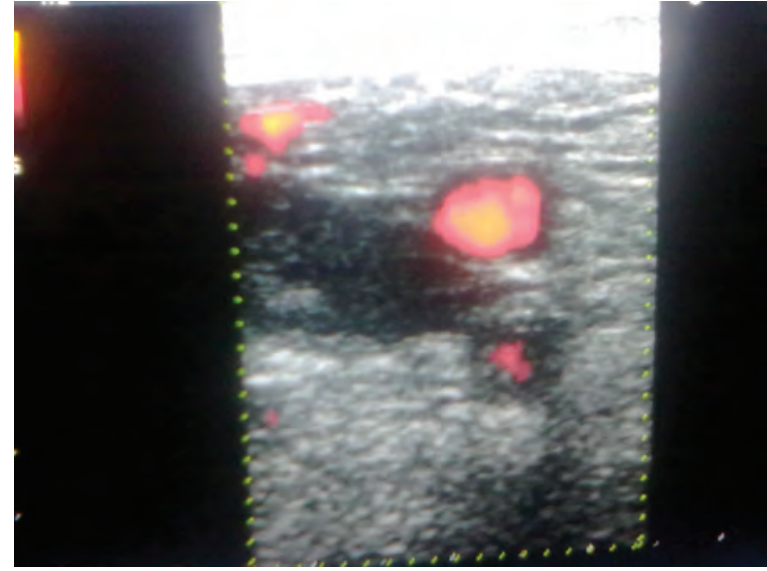

Figure (1): Right common femoral vein (arrow) thrombosis in a 66 years patient with liver cirrhosis.

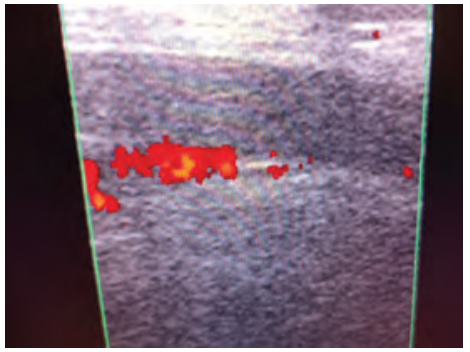

Figure (2): Right popliteal vein thrombosis in a 56 years patient with liver cirrhosis. The image shows completely thrombosed popliteal vein (arrows).

Table (1): Clinical characteristics and laboratory values of cirrhotic patients with and without DVT.

\begin{tabular}{|l|l|l|l|}
\hline \multicolumn{1}{|c|}{$\begin{array}{c}\text { Characteristics } \\
\text { mean } \pm \mathrm{SD}\end{array}$} & $\begin{array}{l}\text { Cirrhotic patients } \\
\text { with DVT }\end{array}$ & \multicolumn{1}{|c|}{$\begin{array}{c}\text { Cirrhotic patients } \\
\text { without DVT }\end{array}$} & P value \\
\hline Age in years & $60.17 \pm 4.17$ & $54.3 \pm 8.46$ & 0.113 \\
\hline Age group $>60$ & $\begin{array}{l}2(33 \%) \\
4(67 \%)\end{array}$ & $\begin{array}{l}21(87.5 \%) \\
3(12.5 \%)\end{array}$ & 0.016 \\
\hline Male/ female N (\%) & $2(33 \%) / 4(67 \%)$ & $10(42 \%) / 14(58 \%)$ & 0.545 \\
\hline Child-Pugh score & $7.8 \pm 3.8$ & $8 \pm 2.8$ & 0.923 \\
\hline Diabetes N (\%) & $4(83.3 \%)$ & $6(25 \%)$ & 0.017 \\
\hline Orthopedic surgery N (\%) & $1(17 \%)$ & $0(0 \%)$ & 0.011 \\
\hline Platelet count & $137 \pm 81$ & $111.5 \pm 30.7$ & 0.471 \\
\hline Prothrombin time (in seconds) & $18 \pm 4$ & $17 \pm 5$ & 0.699 \\
\hline Prothrombin concentration & $70 \pm 12 \%$ & $64 \pm 19 \%$ & 0.517 \\
\hline INR & $1.6 \pm 0.4$ & $1.5 \pm 0.4$ & 0.629 \\
\hline Protein C & $48.8 \pm 11$ & $53.9 \pm 12$ & 0.353 \\
\hline Protein S & $68.8 \pm 13$ & $61.6 \pm 13.5$ & 0.253 \\
\hline Antithrombin III & $57 \pm 15.5$ & $62 \pm 14.8$ & 0.498 \\
\hline Albumin (g/L) & $2.8 \pm 0.6$ & $2.4 \pm 0.8$ & 0.392 \\
\hline
\end{tabular}

and without DVT were compared. The results showed that only older age, diabetes mellitus, and history of lower limb orthopedic surgery were significantly more in cirrhotic patients with lower limb DVT. The coagulation profile showed a decrease in protein $\mathrm{C}$, protein $\mathrm{S}$, antithrombin III as a consequence of liver cirrhosis. The two groups are age, sex, and Child-Pugh score matched with statistically insignificant difference in the levels of serum albumin, prothrombin time and concentration, INR, platelet count, protein C, protein S, and antithrombin III Table(1).

When the diagnosis of lower limb DVT was made, anticoagulation therapy was started in 4 patients and delayed for 3 weeks for the other 2 patients for whom EGD revealed risky esophageal varices and were subjected to endoscopic variceal band ligation. During these 3 weeks the 2 
patients received management in the form of bed rest, leg elevation $45^{\circ}$, and local medication (thrombophobe gel). After 3 months of AT, one patient (Child-Pugh class A) showed complete recanalization of DVT, three patients (Child-Pugh class A,B) showed partial response, and two patients (Child-Pugh class C) died during the follow up period because of liver decompensation (encephalopathy). Anticoagulation therapy was stopped after 3 months whether complete or partial recanalization was obtained. Fortunately no patients suffered severe side effects of AT that require interruption of therapy. Two patients developed anemia because of portal hypertensive gastropathy and received fresh blood transfusion.

\section{Discussion:}

Several mechanisms have been proposed to explain thrombosis in cirrhotic patients including, an acquired deficiency of protein C, protein S, and antithrombin III.5,1,9

In our study the incidence of DVT was $0.96 \%$. Similar results were reported by García-Fuster et al, ${ }^{7}$ and Northup et al, ${ }^{4}$ In our study, the lower limb DVT was found only in the right leg common and superficial femoral and popliteal veins. Also, GarcíaFuster et al, ${ }^{7}$ observed that the right leg was more commonly affected.

We found insignificant difference in the mean prothrombin time and concentration, and INR in cirrhotic patients with and without DVT. The studies conducted by Northup et al, García-Fuster et al, and Gulley et al, reinforces the notion that the perceived coagulopathy in patients with liver disease, as reflected by prolonged INR values, does not protect patients against venous thrombosis. $4,7,3$

The six studied patients had decreased levels of protein $\mathrm{C}$, protein $\mathrm{S}$, and antithrombin III which is mostly acquired due to absence of prior thrombotic event before liver disease. These patients had mean albumin value of $2.8 \pm 0.6 \mathrm{gm} / \mathrm{dl}$ with no significant difference when compared to the cirrhotic controls. In the study by Ben Ari et al, ${ }^{10}$ and Northup et al, ${ }^{4}$ the serum albumin level was independently associated with the occurrence of thrombosis.
We did not find any association between protein $\mathrm{C}$, protein $\mathrm{S}$, and antithrombin III, and the development of lower limb DVT in patients with liver cirrhosis. In liver cirrhosis the concentrations of anticoagulant factors decrease concomitantly with the decrease in coagulation factors. Decreased natural anticoagulants, therefore, could not be considered as a risk factor for developing DVT. There were many other risk factors that predispose to DVT such as age above 60 years, diabetes mellitus, and lower limb orthopedic surgery.

Concerns exist for treating cirrhotic patients as they are at risk of bleeding because of coagulopathy and portal hypertension. ${ }^{11,12}$ LMWH was shown to be effective and safe in the treatment of PVT and other vein thromboses in patients with liver cirrhosis. 13,6 Also, García-Fuster et al, ${ }^{7}$ described the need for anticoagulation in treatment of lower limb DVT in patients with liver cirrhosis.

Our study was not large enough to evaluate the safety of anticoagulation therapy in patients with liver cirrhosis but according to our management protocol no patient suffered from severe side effects of AT. This may be attributed to the continuous trials for improving the general condition of the patients by infusing salt free albumin and correction of anemia by fresh blood transfusion. Also we screened the patients for esophageal varices and prophylactic band ligation was done for two cases before the start of AT.

Despite the coagulation dysfunction, lower limb DVT could still occur in patients with liver cirrhosis. To our knowledge our study is the first prospective study to evaluate the incidence, predisposing factors of lower limb DVT in cirrhotic patients, and evaluate the use of anticoagulation therapy with low molecular weight heparin and vitamin $\mathrm{K}$ antagonist (warfarin) in these patients. All the previous studies had limitation of being retrospective.

\section{Conclusion}

The incidence of lower limb DVT in our cirrhotic patients was $0.96 \%$. Patients with liver cirrhosis may share the same risk factors 
for DVT as other non-cirrhotic patients. The use of AT in cirrhotic patients needs meticulous follow up for early management of any complication and screening for varices with prophylactic band ligation if risk signs were present.

\section{Reference}

1- Amitrano L, Brancaccio V, Guardascione MA, Margaglione M, Iannaccone L, D’Andrea G, Marmo R, Ames PR, Balzano A: Inherited coagulation disorders in cirrhotic patients with portal vein thrombosis. Hepatol 2000; 31: 345-348.

2- Senzolo M, Burra P, Cholongitas E, Burroughs AK: New insights into the coagulopathy of liver disease and liver transplantation. World J Gastroenterol 2006; 12: 7725-7736.

3- Gulley D, Teal E, Suvannasankha A, Chalasani N, Liangpunsakul S: Deep vein thrombosis and pulmonary embolism in cirrhosis patients. Dig Dis Sci 2008; 53(11): 3012-3017.

4- Northup PG, McMahon MM, Ruhl AP, Altschuler SE, Volk-Bednarz A, Caldwell SH, Berg CL: Coagulopathy does not fully protect hospitalized cirrhosis patients from peripheral venous thromboembolism. Am J Gastroenterol 2006; 101(7): 1524-1528.

5- Mammen EF: Coagulation abnormalities in liver disease. Hematol Oncol Clin North Am 1992; 6: 1247-1257.

6- Kearon C, Kahn SR, Agnelli G, Goldhaber S, Raskob GE, Comerota AJ: Antithrombotic therapy for venous thromboembolic disease: American College of Chest Physicians
Evidence-Based Clinical Practice Guidelines (8th ed). Chest 2008; 133(6): 454S-455S.

7- García-Fuster M J, Abdilla N, Fabiá M $\mathrm{J}$, Fernández $\mathrm{C}$, Oliver $\mathrm{V}$ and Forner $\mathrm{M}$ $\mathrm{J}$ : Venous thromboembolism and liver cirrhosis. Rev Esp Enferm Dig 2008; 100(5): 259-2562.

8- Zwiebel WJ: Diagnosis of deep venous thrombosis. In: Introduction to Vascular Ultrasonography. Fourth edition. Zwiebel WJ editor. WB Saunders Company, Philadelphia, USA, 2004.

9- Amitrano L, Guardascione MA, Brancaccio V, Balzano A: Coagulation disorders in liver disease. Semin Liver Dis 2002; 22: 83-96.

10- Ben Ari Z, Panagou M, Patch D, Bates S, Osman E, Pasi J, Burroughs A: Hypercoagulability in patients with primary biliary cirrhosis and primary sclerosing cholangitis evaluated by thrombelastography. J Hepatol 1997; 126: 554-559.

11- Caldwell SH, Hoffman M, Lisman T, Macik BG, Northup PG, Reddy KR, Tripodi A, Sanyal AJ: Coagulation disorders and hemostasis in liver disease: pathophysiology and critical assessment of current management. Hepatol 2006; 44:1039-1046.

12- Northup PG, Sundaram V, Fallon MB, Reddy KR, Balogun RA, Sanyal AJ, Anstee QM, Hoffman MR, Ikura Y, Caldwell SH: Hypercoagulation and thrombophilia in liver disease. J Thromb Haemost 2008; 6: 2-9.

13- Ageno W, Squizzato A: Prophylaxis and treatment of venous thromboembolism in patients with cancer. Intern Emerg Med 2006; 1: 260-262. 